\title{
Arte, Didáctica y Educación
}

\section{Arte, Didactics and Education}

\author{
Rocio Polanía Farfán \\ Aspirante Doctoranda en Estudios Sociales de la Universidad Externado. \\ Universidad Surcolombiana. Neiva. Colombia. \\ educacionartistica@usco.edu.co
}

"Hay algo en el arte que expresa una verdad inmutable. Esto es lo que nos permite a nosotros, hombres del siglo XX, emocionarnos al contemplar pinturas rupestres o al oir canciones antiguas."

Ernst Fischer $(2011,118)$

\section{Resumen}

El arte como actividad requiere un aprendizaje y no puede limitarse a una simple habilidad técnica, debe ampliarse hasta el punto de englobar la expresión de una visión particular o colectiva del mundo. La didáctica heurística propone ampliar los horizontes de la dimensión perceptual creativamente, lo que permite dar un salto en el vacío que separa un conjunto de conocimientos conocidos a uno nuevo y desconocido. Se trata de aprender por descubrimiento, experimentación, aproximación o ensayo, lo que permite imaginar, visualizar utopías que generen nuevos paradigmas, bienes del conocimiento en el campo de la educación artística. Es en este contexto, la didáctica heurística propone un espacio para inventar, crear que no se basa ni en la lógica ni en la combinatoria sino en la sensibilidad y en la imaginación.

Palabras claves: Arte, Didáctica, Heurística, enseñanza, aprendizaje, creatividad.

\begin{abstract}
Art as an activity requires learning and cannot be limited to a simple technical skill; it must be widened to the point of including the expression of a particular or collective vision of the world. The heuristic didactics proposes to widen the horizons of the perceptual dimension creatively, which allows a leap into the dark that separates a set of known knowledge to a new, unknown one. It is about learning by discovery, experimentation, approximation or trial, which allows imagining, visualizing utopias that generate new paradigms, knowledge goods in the field of arts education. It is in this context, heuristic didactics proposes a space to invent, to create that is not based neither in logic nor combinatory, but in sensitivity and imagination.
\end{abstract}

Keywords: Art, didactics, heuristic, teaching-learning, creativity.

Considerar una trilogía arte, didáctica y educación implica ipso facto confluir en una unidad. Bien sabemos que toda unidad es un fractal que se repite a sí misma infinitesimalmente, lo cual significa que la educación debe prepararse para comunicar desde la perspectiva neuronal humana la superdiversidad del mundo que expresan tanto la ciencia como el arte. Por ende, estos no pueden separarse.

Humanizar desde el arte de la mano de la ciencia invita a la complejidad del mundo vivenciado a través de la supercomunicación que experimentan los seres humanos de la actualidad. Así bien, en estos parámetros la educación debe acudir a una didáctica heurística o inventiva que le permita reunir múltiples elementos de manera llana y simple, para evitar confusiones o mezcolanzas intrincadas a la percepción de los educandos.

En esa medida, esta didáctica habrá de evitar los 
preconceptos o la inserción de conceptos en una nueva educación artística en los estadios iniciales. Esto quiere decir que los métodos y estrategias deben ser reestructurados para aprender descubriendo, no exactamente de un modo constructivista, sino por inversión, de modo deconstruccionista experimental. Experimental, porque la experiencia humana es interacción entre la lattice espacio temporal o campo cuántico (realidad física) y el campo neuronal o cerebro humano.

Mas para afrontar estos elementos en una unidad interactuante con otras unidades compuestas, se hace preciso reiterar (sin contradicciones) dichos elementos referencialmente, 0 , lo que es lo mismo, instaurarlos en una célula cuya membrana les garantiza esa unidad. En este sentido, los procesos creativos son connaturalmente holísticos, si se tiene en cuenta que el todo es siempre más que la suma de las partes. Las teorías relacionadas con las obras no pueden ser extraídas del proceso creativo al que pertenecen como heurísticas. Lo que realmente importa es, pragmáticamente, que todo lo que invoca el creador pueda desembocar en el resultado artístico, la obra, la música, la poesía. Contrario a lo que pasa en ciencias, en arte una teoría puede ser validada como heurística en relación a la situación en la que se aplica.

En efecto, el arte como área del conocimiento requiere un aprendizaje para ver, comprender y crear. Por tanto, aplica lo que se ha visto, comprendido y creado hasta el punto de englobar la expresión de una visión particular o colectiva del mundo. No obstante, aquí se propone que este aprendizaje no se limite a las habilidades técnicas, sino que ellas se conviertan en instrumentos de extensión de la percepción humana. Si el hombre extendió su mano a través de la lanza, el arado y otros instrumentos, y la vista a través del microscopio y el telescopio, habrá de extender su percepción, su mente y su conciencia a través del arte. He aquí el presupuesto de la didáctica heurística propuesta: ampliar los horizontes de la dimensión perceptual creativamente.

Sin duda tanto el arte como la ciencia requieren habilidad técnica, las cuales son internalizadas, dominadas hasta tal punto, que pueden ser utilizadas sin prestarles atención consciente. Los artistas y los científicos intentan crear un orden partiendo de las experiencias diversas $\mathrm{y}$, en apariencia, aleatorias del mundo. También pretenden comprenderlo, hacer una valoración de él y transmitir su experiencia a otras personas. Sin embargo, existe una diferencia esencial entre ambas intenciones: los científicos estudian las percepciones de los sentidos de modo cuantitativo para descubrir leyes o conceptos que reflejen una verdad universal. Los artistas seleccionan las percepciones cualitativamente y las ordenan de forma que manifiesten su propia comprensión personal y cultural.

Mientras que las investigaciones posteriores pueden llegar a invalidar leyes científicas, una obra de arte
- aunque cambie el punto de vista del artista o el gusto del público - tiene un valor permanente como expresión estética realizada en un tiempo y en un lugar determinado. Por ello a la educación le concierne una profundización aplicada desde las bases neuronales a nuevas prácticas o didáctica inventiva, que no provenga precisamente del educador sino de manera activa de parte del educando.

Con esa mira, en la didáctica heurística interesan las cualidades del mundo tanto natural como humano, sin olvidar por un instante que lo humano es un hecho natural, pero que aquí se discrimina de manera social y psicológica, es decir, las bellas manifestaciones de las cualidades humanas que hermosean el mundo y lo dotan de condiciones para habitarlo deseablemente. De ahí la importancia de la imaginación del creador la cual permite otorgarle un valor particular a la heurística, entendida como una estrategia de realización de lo que la imaginación propone.

La didáctica heurística propuesta se ve reflejada en un ejemplo histórico que ilustra la pretensión expuesta: una obra de arte denominada Cadáver Exquisito expresó que tanto en las artes plásticas como en la poesía, los surrealistas experimentaron técnicas en que el juego y el azar (condiciones aleatorias del mundo) favorecían el surgimiento de la imagen mediante la libre asociación de elementos no premeditados. El cadáver exquisito, creación colectiva en la que un individuo participa sin conocer la frase o el dibujo que ha hecho otro, constituye, especialmente en los años 1927-1928, una de las innovaciones del grupo.

Esta técnica, junto con otras creadas por las vanguardias del siglo $\mathrm{XX}$, se ha utilizado con frecuencia entre los recursos de nuevas tendencias. Con este ejemplo se hace manifiesta la intención de esta didáctica heurística propuesta que conlleva a una nueva educación artística consistente, no en sacar nada de la nada, sino en una especie de reciclaje o ecología de la mente. Hasta donde el conocimiento permite, "ex nihilo nihil", nada sale de la nada, y en ello se basa la inventiva o la creatividad, en un avisamiento filosófico para esclarecer que el mundo es ilusión, que como hecho cotidiano las apariencias engañan, pero que esas apariencias engañosas son la realidad, una realidad cubierta o revestida que se hace preciso desnudar a fin de tocar su piel, olerla, saborearla o escuchar su palpitar, hasta conocer su verdadera naturaleza desde su propia naturaleza.

He ahí las manifestaciones del arte que la educación habrá de poner ante los sentidos de los estudiantes educados artísticamente. Y es así como se hace posible por esta vía entender las dicotomías entre arte e ilusión, arte y realidad, realidad y ficción, que no difieren precisamente de sus pares.

En aras de esto, la enseñanza o la educación -como presentación sistemática de hechos, ideas, habilidades y técnicas orientada hacia los estudiantes dentro de 
una didáctica heurística- se convierte en un aprendizaje situacional en que la competencia prioritaria del estudiante es proponer desde la obra de arte, desde su estética vivencial, desde su código visual. Ahora bien, esta didáctica propuesta planteada sobre la creatividad ambiciona que si el estudiante no conoce en sus estadios iniciales el lenguaje artístico, lo cree de su talante momentáneamente hasta alcanzar un lenguaje visual más estructurado y universal que pueda contrastar con su código creado.

Ello se hace viable con técnicas tan simples como empezar copiando (tal y como lo proponía el histólogo y precursor de la neurología moderna S. Ramón y Cajal), pues las bases neurológicas de la cognición son las copias. En efecto, una mala copia es el primer paso; a continuación se emplearía una técnica tan simple pero creativa como es la inversión (La inversión es más compleja de lo que parece. Si para un caso el ejemplo es una pintura, no sólo se invierten los tonos y colores, sino las estructuras geométricas, la narración plástica o tantos otros elementos que habrán de ser reconocidos). A continuación se aplicaría la fragmentación o integración con otras obras, lo que daría como resultado un producto "totalmente nuevo".

Si así fuere, a manera de ejemplo, este tipo de educación no comunicaría simplemente una fusión de técnicas, sino que educar artísticamente significaría comunicar el arte como una aventura humana, como una proyección intensa de la expresión profunda de la condición del estudiante. A su vez, esta práctica sugerida cumpliría con un patrón de los seres humanos que han sobrevivido y evolucionado como especie por su capacidad para transmitir conocimiento.

No sobra decir que esto no se haya hecho, sino que es a través de prácticas semejantes a las que se llega a la creatividad que proporciona el arte. Mas no solamente a la creatividad, sino al lema del poeta Horacio: "Prodesse et delectare", instruir deleitando. Maravillosa expresión cuando el aprendizaje se convierte en un placer que de acuerdo con la experiencia el arte es capaz de proporcionar con un grado más alto de intensidad.

Si acordamos que el concepto 'educación' denota los métodos con los cuales una sociedad mantiene sus conocimientos, cultura y valores, y afecta a los aspectos físicos, mentales, emocionales, morales y sociales de la persona, la catarsis u oxigenación que proporciona la educación artística es vital si se encuentran los métodos o estrategias que faciliten esta oxigenación, dirigida a un mejoramiento indudable de la calidad de vida. Mas ese cómo saber enseñar que implica la didáctica, también significa relacionar conocimientos relativos tanto a la educación como a las disciplinas anexas de forma integrada, y no por separado, en una asignatura en cuestión.

En este sentido el arte debe ser revelador en pro del humanismo, pues si la comunicación es un proceso de transmisión y recepción de ideas, información y mensajes, y en ellos van insertos sentimientos y emociones, los estudiantes no deben ignorar que los medios de comunicación tienden bien a reforzar los puntos de vista personales o a modificarlos decisivamente, $y$ que en cualquier caso influyen a largo plazo, de forma sutil pero decisiva, sobre los puntos de vista y el criterio.

Por tan sugestiva razón los estudiantes han de saber que el arte también es un medio de comunicación especial y poderoso. No obstante, no basta con admirar al estudiante frente al arte o lo artístico. Se hace necesario que se cuestione frente a su fenómeno. Pero no que se cuestione desde la teoría, sino desde su vivencia, como un ser recién creado, es decir que comprenda la obra de arte desde su propio análisis morfológico tomando sus partes y reconstruyendo el todo, a fin de sacar sus propias conclusiones para al final contrastarlas con la crítica o la teoría del arte.

¿Qué sería entonces lo artístico para el estudiante, cómo podría definirlo? Antes de definirlo asumiría la función cultural que ejerce en su medio a partir de su esfera no creativa, de su inmediatez y de su actividad humana. Habría de observar su radio de acción, cómo sus efluvios le alcanzan y le transforman o sensibilizan, o sencillamente no le dicen nada. Por supuesto que su radio de acción estaría delimitado por la distancia entre este y la recepción del estudiante.

A ello obedece que la didáctica heurística propuesta no esté interesada en el análisis de obras pues, si bien es un trabajo interesante, resulta difícil para que los estudiantes lo resuelvan. Según Pérez (2002) muchos de los conceptos sobre arte que el maestro maneja con facilidad suelen ser muy abstractos y complicados para los niños y los adolescentes. Incluso, muchas veces personas sensibles e interesadas en el arte se apartan de él por miedo a no saber interpretar correctamente lo que están viendo. (p. 77)

Sin embargo para estas últimas personas pueden ser convenientes ejercicios de interpretación y análisis de obra para evitar que su opinión quede frustrada, en tanto que para los primeros se aconseja una "pequeña colección de obras privadas", armando una carpeta con recortes de revista de fotos de obras que les llamen la atención sin ningún análisis o interpretación. Si bien los ejercicios sí se hacen necesarios para los que se están educando en educación artística, en la didáctica heurística propuesta se sugiere en los primeros estadios el mismo procedimiento.

De otra parte, en una educación artística heurística se hace necesario explorar los universos naturales, sociales y culturales de los estudiantes desde una perspectiva selectiva y sensible-emocional para entrar en la etapa investigativa o científica de la didáctica heurística, pues sin esta información no se hace posible innovar la didáctica propia. Mas para explorar esos mundos se requiere cumplir unas condiciones mínimas que de acuerdo con Ubals (2004) se deben 
exigir en el proceso de la categoría artística:

1. "Participar de la creación de una "nueva realidad y un nuevo lenguaje", cuando el lenguaje común se paraliza.

2. Dar a conocer a través de las posibilidades que ofrece la llamada imagen artística un determinado nivel de conocimiento, comunicación e información interactiva para los estudiantes.

3. Lograr espacios de catarsis, en el sentido de la capacidad que tiene para "oxigenarnos" de determinados efectos negativos mediante semejantes vivencias ficticias y recreadas armónica y proporcionalmente.

4. Lograr efectos compensatorios, al lograr mediante los códigos con que opera "purificar nuestras almas" de los embates convulsos de la vida cotidiana.

5. De coadyuvar a determinado nivel de educación a través de iuegos y entretenimiento en los estudiantes.

6. Influir en el subconsciente del estudiante, de formación de un determinado espíritu creador y de perfeccionamiento del gusto estético de los mismos" (P. 7)

El estudiante participa justamente creando su propio lenguaje que en otro estadio más complejo cotejará con otros lenguajes afines a su creación. La información interactiva será suministrada decantadamente al estudiante asentada en su propia imagen artística.

Su catarsis será extraída desde sus vivencias ficticias narradas en su arte incipiente. Hallará compensación de la abstracción del arte expresada en su vida cotidiana. Por último aprenderá a extraer de su mundo onírico, de lo que cree sobre sí su espíritu creador, interactuando así con su conciencia discontinua que suscita su inconsciente.

En esta medida se va configurando la didáctica heurística propuesta, frente a un mundo desconocido para el estudiante y que se manifiesta como un proceso enigmático el cual, a diferencia del resto de los valores que tiene su micromundo de actuación, le permitirá descubrir que los valores artísticos fluctúan en cuatro macromundos: la naturaleza, la sociedad, él y el arte. Un nivel de relación valorativa que permite que los universos (la naturaleza, la sociedad, el hombre y el arte) con los que trabaja se vean sustancial e integralmente reflejados en cada una de las concretitudes de lo real.

$Y$ es desde las concretitudes de lo real que el estudiante averiguará que el mundo no es una conformación de parcelas sino una unidad cuya puerta es abierta por lo figurativo, lo idealizado o lo abstractivo del arte. A ello se debe que Herbert Read afirmara que el arte, ampliamente concebido, debería ser la base fundamental de la educación, pero este entendido como puente integrador de realidades o cotidianidades, de aprendizajes y nuevas concepciones.

Dice Pérez (2002) que la educación en el campo de la visualidad busca desarrollar la creatividad a través de la investigación de los elementos plásticos que son usados para representar imágenes, reales o imaginarias, figurativas o abstractas (p. 115). El estudiante sabrá entonces que el mundo es una representación transmitida por su herencia biológica y cultural, pero ante todo una representación suya o que puede hacer suya.
Pero si bien el estudiante halla la unidad de las cosas en la representación del mundo o de su mundo, hallará también en ella la diversidad, en particular con la técnica deconstruccionista. Cuando Derrida (citado por Efland, 2003) definió el impulso deconstructivista como <<buscar un texto dentro de otro, disolver un texto en otro o construir un texto en otro >>, también sugirió el <<collage/montaje como la principal forma del discurso posmoderno. (p. 183)

En efecto, esta técnica nada despreciable permite incrementar la creatividad en el método didáctico heurístico propuesto, pues el discurso artístico o su correlato creado por el estudiante mediante esta práctica incursiona en los lineamientos posmodernos, que rechazan lo lineal y admiten el bucle en cualquier aspecto del fenómeno del mundo de la vida, permitiendo el eclecticismo, posibilitando una belleza disonante derivada de la combinación de motivos ornamentales clásicos y de otros estilos, al tiempo que produce significados ambiguos o contradictorios y deja contemplar al estudiante que la realidad presenta varios sentidos, que la decisión aprecia varias opciones, que los fenómenos tienen varias explicaciones y jamás sólo una.

En definitiva, le invita a conocer un mundo de posibilidades que le abrirán una percepción ampliamente humana y real sobre la huida de las cosas y los seres en el espacio-tiempo cuyas dimensiones conectan con realidades insospechadas y diversas. En este sentido Cage \& Reynolds (1998) afirma que, muchas veces digo que yo no tengo ningún objetivo, pero evidentemente este no es el caso. Y, sin embargo, sí lo es. Creo que eliminando el objetivo, aumento la percepción. Por lo tanto mi objetivo, es desembarazarme del objetivo. (p.13)

¿Y cómo no ha de ser de otra manera si el estudiante llega a comprender preclaramente que su representación del mundo manifestada en una creación artística es su propia expresividad, signo del latido apasionado de su vida en bucles que retoñan probándole una alta probabilidad de inmortalidad? Sin que sea necesario para él conocer los planos semióticos, los experimentaría en sus experiencias catalizadoras de su conciencia naciente, in crescendo, porque está hallando finalidades o funciones buscadas motu propio, con aptitudes autodescubiertas por elementos visibles que antes le eran invisibles y la satisfacción de que con el arte puede invisibilizar intenciones para descubrir otros objetos no intencionados. Más tarde sabrá que ha manipulado la semántica, la sintaxis y la pragmática sin nominarlas, pero que ahora son indelebles en su conciencia. Descubrimientos tan sencillos en esta didáctica heurística le proporcionarán un placer tan profundo, que comprenderá cuando llegue su momento el aforismo de Nietzche que reza: "el placer requiere de profunda, profunda eternidad".

A decir verdad, en estas instancias el estudiante esgrimirá las dimensiones humanas que le constituyen 
cuando aprehenda, por caso, su dimensión psicológica o parte de ella, cuando se vea instado a plasmar su autoexpresión narcisista, o bien su dimensión social en lo que tiene su personalidad de política, de religiosa, de ética, de erótica, de sentimental o de nacionalista. Y extraordinario será cuando discierna entre lo mimético y lo creativo, y ejerza ya prácticas y recombinaciones entre ambas.

Así las cosas, la didáctica heurística aspira tras las primeras instancias lograr no meramente el cambio conceptual constructivista, sino el cambio perceptual, entendiendo que la percepción no es sólo lo que se tiene físicamente delante de los sentidos, sino también lo que el cerebro hace con esa información. En ese camino, el estudiante ha de aprender que él vive en el mundo que ve, pero que el mundo que ve no es el mundo material que le rodea, sino el que percibe en su mente, que el mundo físico puede ser exactamente el mismo pero distintas personas verán distintas cosas.

Ese será su mejor entrenamiento sobre el juicio que el arte le puede otorgar gratuita y gozosamente. Es bajo estas experiencias estético-éticas que el estudiante comprenderá el mundo subjetivo de los prejuicios y los conflictos desde su dimensión psicológica, pero que dentro de la didáctica heurística aprenderá de ellos mi concepto - no tu concepto, mi percepción - no tu percepción en una resolución de conflictos emergentes positivos.

Así bien, dentro de una didáctica heurística el estudiante irá paulatinamente absorbiendo y recreando su propio mundo de la vida desde su contexto social y cultural, en paralelo a los contextos que le ofrece la supercomunicación. Su creatividad incrementará decisivamente si busca un texto-imagen en otro, si lo disuelve en otro, o lo construye en otro texto-imagen, vertiendo su propio montaje-mundo.

De los muchos elementos recursables dentro de la didáctica heurística no deben descuidarse los que conciernen al enfoque de la cultura visual. Ello estriba en lo que atañe a las bases biológicas de la visión, en la fisiología misma del ojo y lo que le corresponde a la percepción por vía del cerebro.

Es bien sabido que para la mayoría de la gente la visión es el más importante de todos los sentidos. En efecto, en el cerebro el área dedicada a los mecanismos de la visión es mayor que la de ningún otro sentido, lo que la gente ve le proporciona un ochenta por ciento de toda la información que tiene sobre el mundo, de donde se desprende que:

El enfoque de la cultura visual ofrece dos ventajas importantes para la educación artística: a) es capaz de conectar directamente con situaciones y debates estrictamente coetáneos en las zonas emergentes del arte y las teorías del arte, y siempre es preferible acompasar lo que sucede en la escuela con lo que sucede en la sociedad, b) Permite concentrarse en las imágenes más atractivas y fascinantes para el alumnado: muñecos y muñecas, videojuegos, páginas web, parques temáticos y de atracciones, cadenas multinacionales de restaurantes de comida rápida, teleseries, pegatinas, dulces y golosinas, ropa. (Viadel, 2003, p. 42)
Esto conlleva a una didáctica heurística de la explotación. Si la tele, internet y el cine son tan seductores, estratégicamente la educación artística debe valerse de esas fascinaciones para enseñar, disfrutar y revelar. Pero de otro lado, si se erige como una didáctica de la invención, se hace preciso explotar los bajos umbrales de los otros sentidos para lograr efectos creativos, e incluso potenciar a la visión que siendo el sentido más poderoso fisiológicamente deviene en el órgano que padece la ceguera social, psicológica y cultural. Esta ceguera, que además de ser una de las premisas de los evangelios, se convierte en una aguda premisa en el libro "Ensayo Sobre la Ceguera" de José Saramago. ¿No debe entonces la educación artística tomar cartas sobre el asunto de aquellos campos visuales que necesitan la luz?

El consumo es un problema radial de las sociedades, se consume visualmente, ¿por qué entonces dentro de la canasta familiar las familias no consumen un telescopio o un microscopio, instrumentos que suministran a la percepción realidades que subyacen en la realidad física? Qué hermoso sería que un estudiante plasmara cromáticamente o plásticamente la estructura microscópica de una hoja, o un fragmento rocoso de la luna adentrándose en la fractalidad de las estructuras físicas o de la energía. El ojo de los seres humanos ve energía electromagnética en forma de ondas luminosas, el arte es capaz de fijarlas, de retenerlas en una bella captura visual que puede ser comunicada a los ojos del mundo que comunican de sí esa misma realidad ahora revertida.

Podría concluirse entonces que el esplendor de las artes, de esa enigmática expresión humana asumida en una didáctica de la educación artística (didáctica heurística), así como propone estrategias sugeridas y paradigmáticas, también debe proponer pasos para hacer que el talento crezca, pero evitando los obstáculos que coartan la creatividad, tantos, pero entre ellos: "La rutina, las actitudes autoritarias, la intolerancia y la hostilidad contra la personalidad distinta; la rigidez de la personalidad, porque inhibe las expresiones creativas; la excesiva exigencia por pedir respuestas correctas, la intolerancia a la actitud del juego, etc." (Pérez, 2002, p. 86). Tales pasos deben ser remitidos asertivamente a los estudiantes educados artísticamente. Mas de una manera especial y trascendente, de modo que esa remitencia les dé lo más fastuoso del arte, eso, como una música o una poesía, que nada puede arrebatarles porque lo llevarán en el cuerpo y en la mente ya que el arte es vida pura, eminentemente fluida, contingente y totalmente irreducible en términos de conceptos.

\section{Referencias Bibliográficas}

Cage J. \& Reynolds, R. (1988) Entretien (1961), traducción al francés de Madeleine Chantoiseau in Revue d'esthétiqu e no 13-14-15, ediciones Privat.

Efland, A. (2003) La educación en el arte posmoderno. Ediciones Paidos Ibèrica S.A. Barcelona.

Fischer, Ernst. (2011) La necesidad del arte, Ediciones Peninsula. Barcelona- 
Pérez, I. (2002) La didáctica de la educación plástica. El taller de arte en la escuela. Editorial Magisterio de Río de la Plata.

Ubals, José Manuel. (2006) Educación Estética y Educación Artística: Un diálogo no agotado desde la "infinitud cercana". Universidad Pedagógica "Raúl Gómez García" Guantánamo, Cuba. www.centrodemaestros.mx/.../Educacionesteticayeducacionartis tica.pdf. Consultado 1/12/2014

Viadel, M. (2003) Coordinador. Didáctica de la educación artística. Pearson Prentice Hall. Madrid. 